\title{
Kekerasan Simbolik Melalui Dominasi Modal Agama pada Sekolah Swasta di Kabupaten Bantaeng
}

\author{
Suardi \\ Program Studi Pendidikan Sosiologi, Universitas Muhammadiyah Makassar \\ Email: suardi@unismuh.ac.id
}

\begin{abstract}
Abstrak
Disparitas antara siswa sekolah swasta dan siswa sekolah negeri menjadi hal biasa karena perbedaan akumulasi modal ekonomi, sosial, budaya, simbolik dan agama. Artikel ini bertujuan untuk menganalisis dan menemukan adanya modal agama sebagai bentuk akumulasi modal untuk mengatasi kekerasan simbolik. Penelitian ini dilakukan menggunakan metode mixed method concurrent embedded di 10 sekolah swasta dan 6 sekolah negeri. Informan penelitian kualitatif sebanyak 43 orang ditentukan menggunakan purposive sampling sedangkan responden penelitian kuantitatif sebanyak 301 orang ditentukan menggunakan random sampling. Pengumpulan data dilakukan dengan menggunakan lembar angket skala likert dan Gutman, lembar observasi secara langsung, lembar wawancara terstruktur dan dokumen. Data kualitatif yang telah dikumpulkan dianalisis melalui tahapan reduksi data, display data kemudian melakukan penarikan kesimpulan. Data kuantitatif dianalisis melalui tahapan verifikasi, tabulasi dan persentase data. Hasil penelitian menunjukkan modal agama menjadi hal yang dominan yang dimiliki oleh sekolah swasta yang bisa dioptimalkan untuk merebut dominasi dalam ranah pendidikan agar siswa tidak mengalami kekerasan simbolik. Bentuk modal sosial yang dimiliki oleh sekolah swasta adalah (i) kepercayaan masyarakat terhadap sekolah swasta dalam memberikan pembelajaran agama, karakter atau nilai-nilai sosial, dengan persentase $71.77 \%$, (ii) kepemimpinan spiritual yang selalu didominasi oleh aktor-aktor sekolah swasta dalam berbagai kegiatan keagamaan, dengan persentase $83.05 \%$.
\end{abstract}

Kata kunci : dominasi; modal agama; kekerasan simbolik; akumulasi modal

\section{Symbolic Violence Through Domination of Religious Capital on Private Schools in Bantaeng District}

\begin{abstract}
Disparities between private school students and public school students are common because of differences in the accumulation of economic, social, cultural, symbolic and religious capital. This article aims to analyze and find the existence of religious capital as a form of capital accumulation to overcome symbolic violence. This research was conducted using the mixed method concurrent embedded method in 10 private schools and 6 public schools. Qualitative research informants as many as 43 people were determined using purposive sampling while 301 quantitative research respondents were determined using random sampling. Data was collected using a Likert and Gutman scale questionnaire, direct observation sheets, structured interview sheets and documents. The qualitative data that has been collected is analyzed through the stages of data reduction, displaying the data and then drawing conclusions, while the quantitative data is analyzed through the stages of verification, tabulation and data percentage. The results of the study show that religious capital is the dominant thing owned by private schools which can be
\end{abstract}


optimized to seize dominance in the realm of education so that students do not experience symbolic violence. The forms of social capital owned by private schools are (i) public trust in private schools in providing religious learning, character or social values, with a percentage of $71.77 \%$, (ii) spiritual leadership which is always dominated by private school actors in various fields. religious activities, with a percentage of $83.05 \%$.

Keywords : domination; religious capital; symbolic violence; capital accumulation

\section{LATAR BELAKANG}

Kekerasan merupakan satu istilah yang mengarahkan pada sebuah peristiwa yang mengerikan, menakutkan, menyakitkan, atau bahkan mematikan. Fenomena kekerasan saat ini telah mewarnai hampir seluruh aspek kehidupan sosial mulai politik, budaya, hingga pendidikan. seperti kasus kekerasan seksual terhadap anak yang jamak terjadi (Nursalam et al., 2018). Tak hanya kekerasan dalam arti fisik, terdapat bentuk lain kekerasan yang terus mengemuka yaitu kekerasan simbolik.

Kekerasan simbolik bisa dimaknai sebagai bentuk pemaksaan ideologi atau habitus kelas dominan terhadap kelas yang didominasi, seperti kekerasan simbolik terhadap mahasiswa (Suardi, Agustang, \& Jumadi., 2020a), dan kekerasan simbolik terhadap siswa (Suardi, Agustang, \& Jumadi., 2020b). Hal tersebut menunjukkan bahwa kekerasan adalah masalah yang sangat serius yang terjadi dalam dunia pendidikan, bukan hanya kekerasan dalam bentuk fisik dan psikis namun sudah dalam kekerasan simbolik (Suardi, Agustang, \& Jumadi., 2020a), Kekerasan adalah bentuk masalah sosial yang harus diatasi (Nursalam \& Syarufuddin., 2016), karena merupakan bagian dari penyimpangan sosial (Suardi, 2018).

Konsep kekerasan simbolik (Bourdieu, 1993) menjelaskan mekanisme yang digunakan kelompok kelas atas yang mendominasi struktur sosial masyarakat yang berada pada struktur yang berbeda secara hirarkis untuk "memaksakan" ideologi, budaya, kebiasaan, atau gaya hidupnya kepada kelompok kelas bawah yang didominasinya. Perbedaan sumber daya acap kali terjadi antara pelaku dan korban. Kekerasan simbolik adalah model dominasi kultural dan sosial yang berlangsung secara tidak sadar (unconscious) dalam kehidupan masyarakat yang meliputi tindakan diskriminasi terhadap kelompok/ ras/ suku/gender yang dilakukan oleh aktor atau lembaga yang memiliki kekuasaan, pengetahuan dan modal (social capital, cultural capital, economic capital, symbolic capital) dalam suatu arena (field), akumulasinya membentuk suatu praktik sosial (Bourdieu, 1993).

Kekerasan simbolik ini massif terjadi terjadi berdasarkan hasil observasi, dokumentasi dan wawancara awal peneliti di tahun 2018 khususnya pada masyarakat Kecamatan Bissappu Kabupaten Bantaeng. Peneliti melihat dengan jelas berbagai fenomena sosial yang mengindikasikan sekaligus menjadi embrio kekerasan simbolik. Salah satu yang menarik adalah perbedaan akumulasi modal antara sekolah swasta dengan siswa yang berada pada sekolah negeri dan siswa sekolah swasta. Meskipun setiap masyarakat memiliki modal ekonomi, budaya, sosial (simbol) dalam suatu arena (field) yang membentuk suatu praktik sosial (Bourdieu, 1993). Individu maupun kelas sosial membutuhkan kekuatan simbol sebagai modal kuasa untuk menjalani, mengubah dan membentuk kehidupan tanpa harus melakukan kekerasan simbolik (Larson et al., 2003).

Sekolah Negeri dianggap memiliki modal sosial (social capital), modal budaya (cultural capital), modal ekonomi (economic capital) dan modal simbolik (symbolic

$$
\text { Jurnal Sosiologi Pendidikan Humanis 156 | } 165
$$


capital) (Suardi, Agustang, \& Jumadi., 2020b) yang lebih tinggi sehingga melakukan pemaksaan habitus, agar sekolah swasta mengikuti habitus sekolah Negeri (kekerasan simbolik/symbolic violence) dengan disparitas akumulasi modal yang jauh berbeda. Untuk menganalisis akumulasi modal ekonomi, budaya, sosial, simbolik sebagai faktor penyebab kekerasan simbolik menggunakan teori Pierre Bourdieu tentang akumulasi modal (ekonomi, budaya, sosial, simbolik) (Suardi, Agustang, \& Jumadi., 2020b)

Penelitian sebelumnya menunjukkan bahwa masyarakat terkhusus dunia pendidikan tidak terlepas dari kekerasan simbolik karena akumulasi modal ekonomi, budaya, sosial, simbolik seperti kekerasan simbolik mahasiswa dalam proses perkuliahan (Suardi, Agustang, \& Jumadi., 2020a), kekerasan terhadap siswa dalam proses pendidikan di sekolah (Suardi, Agustang, \& Jumadi., 2020b). Kedua hasil penelitian tersebut menunjukkan kekerasan simbolik terjadi karena adanya akumulasi modal yang berbeda. Namun yang membedakan hasil penelitian ini adalah analisis akumulasi modal agama sebagai bentuk akumulasi modal baru, sehingga penelitian ini merupakan penelitian yang menghasilkan temuan bersifat "orisinal". Hal tersebut penting diteliti karena penelitian ini akan memberikan beberapa kontribusi diantaranya adalah kontribusi terhadap penelitian yang telah ada dalam domain akumulasi modal bukan hanya modal ekonomi, budaya, sosial, simbolik namun juga modal agama. Modal agama termasuk karakter siswa sekolah swasta yang selalu dikembangkan melalui kolaborasi sosial (Suardi, Agustang, \& Sahabuddin, 2020).

Ada beberapa faktor yang menjadi dasar penelitian yaitu (1) latar belakang sosial yaitu perubahan masyarakat yang lebih fanatik terhadap sekolah negeri dan diskriminatif terhadap sekolah swasta. (2) Latar belakang intelektual yaitu konstruksi gerakan perubahan menuju kesetaraan kelas antara siswa/ sekolah swasta dengan siswa/ sekolah Negeri melalui misi perubahan dan pemberdayaan. (3) Latar belakang penelitian yaitu kekosongan teori Pierre Bourdieu dalam melihat akumulasi modal dari aspek modal agama. Berdasarkan hal tersebut perlunya filosofi research dalam upaya pengembangan ilmu pengetahuan, maka problem statement adalah (1) secara ontologi sosiologis menjadikan akumulasi modal ekonomi, budaya, sosial, simbolik sebagai area of knowledge dan ontologi metodologi melihat realitas sosial secara mikro-makro, struktur -aktor, subjek-objek, (2) secara epistemologi sosiologi menggunakan paradigma kritis (prakxis : analisis dan aksi) dan epistemologi penelitian menggunakan paradigma mixed method (kualitatif-kuantitatif), (3) secara aksiologi menghasilkan value secara sosiologis yaitu modal agama, dan menghasilkan value secara metodologis yaitu non free value, emansipatoris dan transformatif, sehingga peneliti tertarik untuk melakukan penelitian ini.

\section{METODE PENELITIAN}

Penelitian ini menggunakan metode penelitian campuran (mixed methods). Model mixed methods concurrent embedded (Creswell, 2017), merupakan gabungan paradigma positivistik dan post positivistik (Nursalam \& Syarufuddin., 2016), Dalam penelitian ini tahap pertama menggunakan metode penelitian kualitatif dan tahap kedua menggunakan metode penelitian kuantitatif secara simultan atau bersama-sama namun dengan bobot yang berbeda. Tempat penelitian atau lokasi penelitian secara umum di Kecamatan Bissappu Kabupaten Bantaeng, yang memiliki 6 sekolah swasta dan 6 sekolah negeri. Instrumen metode kualitatif menggunakan peneliti sebagai instrumen utama dengan menggunakan daftar cek pedoman observasi, pedoman wawancara, 
lembar dokumentasi, kamera foto atau video dan alat perekam. Sedangkan metode kuantitatif menggunakan angket yang sudah divalidasi. Informan metode kualitatif peneliti menggunakan purposive sampling yang berjumlah 43 yang terdiri dari pemerintah, tokoh masyarakat, siswa sekolah negeri, guru sekolah negeri, kepala sekolah negeri, alumni sekolah negeri, siswa sekolah swasta, guru sekolah swasta, kepala sekolah swasta dan alumni sekolah swasta. Sedangkan responden penelitian metode kuantitatif menggunakan teknik simple random sampling yang berjumlah 301 dari 1221 jumlah populasi. Data primer didapatkan secara langsung seperti data hasil wawancara, angket maupun observasi, sedangkan data sekunder adalah data yang didapatkan dari dokumen-dokumen terkait penelitian. Teknik pengumpulan data yang digunakan adalah penyebaran angket model tertutup, observasi langsung, wawancara terpimpin, catatan lapangan dan dokumentasi. Analisis data kualitatif dilakukan melalui tahapan reduksi data, display data dan penarikan kesimpulan, sedangkan data analisis data kuantitatif menggunakan verifikasi kuesioner, tabulasi data kuesioner dan persentase data kuesioner. Keabsahan data kualitatif menggunakan triangulasi sumber, triangulasi waktu dan triangulasi metode, sedangkan data kuantitatif melalui uji reliabilitas (ketepatan) dan uji validasi (benar) (Creswell, 2017).

\section{HASIL DAN PEMBAHASAN \\ Kepercayaan Masyarakat terhadap Sekolah Swasta}

Kepemilikan modal agama yang berbeda antara sekolah negeri dan sekolah swasta mencakup kepercayaan dan kepemimpinan spiritualitas. Sekolah swasta baik berbasis madrasah dan pesantren memiliki modal agama yang lebih bagus dibandingkan dengan sekolah negeri. Hasil wawancara yang dilakukan dengan 43 informan terdiri dari pemerintah, siswa, guru, kepala sekolah, alumni baik sekolah swasta maupun sekolah negeri diperoleh data yaitu ada positif impresi dari masyarakat terhadap sekolah swasta sebagai sekolah yang berbasis agama. Sekolah swasta khususnya yang berbasis agama, secara otomatis mata pelajarannya lebih banyak yang bernuansa agama dengan porsi yang besar dibanding pelajaran umum. Sebagai contoh dalam sekolah swasta Islam (pesantren maupun madrasah) ditemukan pelajaran alqur'an hadits, aqidah, akhlak, fiqh dan mata pelajaran lainnya yang tidak dipelajari pada sekolah negeri.

Pada sekolah negeri porsi pelajaran agama hanya ada pada mata pelajaran pendidikan agama saja (agama Islam misalnya). Dari sini siswa sekolah swasta lebih menguasai banyak hal dengan struktur kurikulum yang lebih besar baik yang fokus pada mata pelajaran bersifat umum seperti biologi, fisika, matematika ditambah dengan ragam pelajaran agama lainnya. Lainnya, interaksi dengan guru atau ustadz di sekolah swasta berbasis keagamaan lebih besar porsi jam interaksinya baik formal maupun informal yang pada gilirannya siswa sekolah madrasah dianggap memiliki sikap spiritual yang jauh lebih baik termasuk pemahaman agama yang lebih dalam karena diampu oleh guru/ustadz yang juga memilikik pemahaman agama yang tinggi. Kegiatan sekolah pada gilirannya juga diarahkan untuk pengembangan kemampuan agama baik dari sisi pengetahuan, sikap maupun keterampilan siswa.

Di Kabupaten Bantaeng dalam tiga tahun terakhir, masyarakat mulai berbondong-bondong menyekolahkan anak mereka ke pesantren, sehingga dari waktu ke waktu tren memasukkan anak ke pesantren terus meningkat. Banyak sekali orang tua yang mau menyekolahkan anak mereka di pesantren dengan ragam rasionalitas. 
Bukan hanya karena kemampuan agama yang diyakini memiliki porsi yang besar tetapi juga prestasi yang ditorehkan oleh siswa yang ada di pesantren di bawah pengelolaan kementerian agama lebih baik. Ditambah Kementerian Agama memiliki tagline yang begitu membumi melalui program "madrasah lebih baik, lebih baik madrasah" dan "ayo mondok". Narasi ini terus dibangun baik melalui word of mouth maupun melalui media sosial. Informasi ini terus diinternalisasikan sehingga informasi tersebut sampai ke ana dan orang tua yang akhirnya membuat orang tua memasukkan anaknya ke pondok pesantren atau sekolah yang memiliki basis agama yang bagus. Salah satu contoh sekolah yang populer di masyarakat Bantaeng berbasis IT (Islam Terpadu) adalah sekolah Wahdah Islamiah yang termasuk sekolah berbasis agama. Sekolah ini cukup populer di masyarakat dengan bentuk pondok pesantren. Secara garis besar, kegiatan dimulai dengan pelajaran agama, kemudian pelajaran umum dan diakhiri pelajaran agama dalam satu hari dengan porsi pelajaran agama lebih besar daripada pelajaran umum. Orang tua jika mau membuat anaknya memiliki pemahaman agama maka ia akan memasukkan ke sekolah swasta yang berbasis agama (madrasah atau pesantren) karena di sekolah agama basis porsi kurikulumnya adalah $70 \%$ mata pelajaran agama, sisanya yaitu $30 \%$ mata pelajaran umumnya. Sebaliknya, jika menghendaki anaknya memiliki pengetahuan akademik atau materi umum dengan porsi besar maka orang tua akan memasukkan di sekolah negeri dengan porsi mata pelajaran agama hanya $10 \%$ sedangkan sisanya adalah mata pelajaran umumnya $90 \%$.

Hasil observasi peneliti dalam aktivitas sosial masyarakat di Kecamatan Bissappu diperoleh data yaitu masyarakat memiliki kepercayaan tinggi kepada sekolah swasta yang berstatus pesantren dan madrasah untuk mendidik anak mereka memiliki pengetahuan agama. Ada lurah bonto langkasa yang memilih menyekolahkan anaknya ke sekolah swasta dibandingkan ke sekolah negeri. Terdapat pula putra kepala Sekolah Menengah Atas (SMA) Negeri 2 Bantaeng yang menyekolahkan ke pesantren agar anaknya mendapatkan pemahaman agama yang tidak didapatkan pada sekolah negeri. Kepala SMAN 1 Bantaeng menyekolahkan anaknya di pesantren agar anaknya mendapatkan pemahaman agama. Masyarakat melihat siswa sekolah swasta memiliki pengetahuan agama yang lebih baik karena siswa sekolah swasta yang berasal dari pesantren sudah bisa menjadi imam masjid dan penceramah ketika mereka kembali ke masyarakat. Hal tersebut menjadikan aktor pada sekolah swasta memberikan label agama sebagai media sosialisasi kepada masyarakat, sekaligus di saat yang sama menjadikan simbol agama menjadi daya tarik kepada masyarakat mulai dari memiliki visi, misi dan tujuan yang lebih cenderung bernuansa agamis. Pelajaran yang digunakan juga cenderung bernuansa islami dan porsinya yang dihadirkan juga cukup besar dan spesifik seperti mata pelajaran Al-Qur'an Hadits, Akidah Akhlak, Fiqih, sejarah kebudayaan Islam, kemuhammadiyahan, Bahasa Arab dan mata pelajaran agama spesifik lainnya tergantung dari sekolah swasta masing-masing.

Berbeda dengan sekolah negeri yang lebih banyak fokus pada mata pelajaran umum dan hanya menggunakan mata pelajaran Pendidikan Agama Islam sebagai salah satu mata pelajaran dengan ciri khas agama. Ada labeling positif untuk sekolah swasta sebagai“sekolah berbasis agama", "sekolah pencetak penghafal AI-Qur'an", "sekolah calon penceramah atau ustadz/ustadzah" sedangkan untuk siswa adalah "siswa penghafal Al-Qur'an, siswa penceramah, hingga label sebagai ustadz atau ustadzah. $\mathrm{Hal}$ ini jelas berbeda bilamana anak sekolah pada sekolah negeri. 
Diagram 1. Kepemilikan modal agama sekolah swasta dalam hal kepercayaan masyarakat

\section{Sekolah swasta lebih dipercaya masyarakat dalam memberikan pemahaman agama}

80

60

40

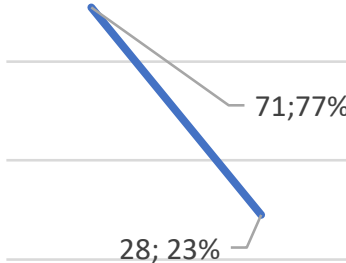

O

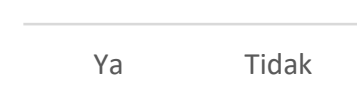

Sumber: Hasil Penelitian

Kepemilikan dan basis modal agama yang berbeda antara sekolah negeri dan sekolah swasta mencakup kepercayaan dan kepemimpinan spiritualitas. Sekolah swasta yang berstatus madrasah dan pesantren memiliki modal agama yang lebih bagus dibandingkan dengan sekolah negeri dengan pembedaan pada struktur kurikulum baik yang nampak maupun tidak nampak. Tingkat kepercayaan kepada sekolah swasta juga lebih tinggi dinbandingkan dengan negeri. Hal tersebut berdasarkan hasil angket dengan 301 informan yang disebar oleh peneliti (lihat diagram 1). Sedangkan pada level kategorisasi. Akumulasi kepemilikan modal agama dalam hal kepemilikan kepercayaan masyarakat yang dimiliki sekolah swasta dan sekolah negeri cukup berbeda. Pada sekolah negeri modal agama dalam hal kepercayaan masyarakat terhadap sekolah swasta dalam memberikan pemahaman agama masuk kategori tinggi. Berbeda signifikan dengan modal agama dalam hal kepercayaan masyarakat terhadap sekolah negeri dalam memberikan pemahaman masuk kategori kurang tinggi (lihat tabel 1). Disparitas ini tentu memberikan pemahaman bahwasanya sekolah swasta lebih diminati masyarakat setempat.

Tabel 1. Kepemilikan modal agama sekolah swasta dan sekolah negeri dalam hal kepercayaan masyarakat

\begin{tabular}{|c|c|c|c|c|}
\hline No. & $\begin{array}{c}\text { Interval } \\
\text { respon }\end{array}$ & Kategori & $\begin{array}{c}\text { Sekolah } \\
\text { Negeri }\end{array}$ & $\begin{array}{c}\text { Sekolah } \\
\text { swasta }\end{array}$ \\
\hline 1 & $81-100$ & $\begin{array}{c}\text { Sangat } \\
\text { Tinggi }\end{array}$ & - & - \\
\hline 2 & $61-80$ & Tinggi & - & 71.77 \\
\hline 3 & $41-60$ & $\begin{array}{c}\text { Sedang- } \\
\text { Sedang }\end{array}$ & - & - \\
\hline 4 & $21-40$ & $\begin{array}{c}\text { Kurang } \\
\text { Tinggi }\end{array}$ & 28.23 & - \\
\hline 5 & $0-20$ & \multicolumn{2}{|c|}{ Tidak Tinggi } & - \\
\hline
\end{tabular}

\section{Kepemimpinan Spiritual}

Selain kepercayaan sebagai modal agama, kepemimpinan spiritual juga menjadi modal agama bagi sekolah swasta untuk memperoleh dominasi dalam masyarakat 
terutama dalam konteks pendidikan. Berdasarkan hasil wawancara yang dilakukan dengan 43 informan terdiri dari berbagai elemen mulai dari pemerintah, siswa, guru, kepala sekolah, alumni baik sekolah swasta maupun sekolah negeri didapatkan bahwasanya orang-orang sekolah swasta itu merupakan tokoh-tokoh masyarakat yang memiliki pengaruh di masyarakat seperti terdapat guru yang merupakan imam masjid, ada juga guru yang merupakan guru ngaji di kampung. Terdapat juga guru yang menjadi ustadz dan ustadzah, menjadi penceramah dalam acara kematian, penceramah dalam acara pernikahan, menjadi pembaca Al-Quran dalam acara peringatan hari kelahiran Nabi Muhammad SAW, khatib pada hari jum'at, penceramah pada hari raya Idul Fitri dan Idul Adha dan ada guru yang merupakan ketua RT dan RW bahkan pemerintah desa. Hasil observasi peneliti dalam aktivitas sosial masyarakat di Kecamatan Bissappu yaitu alumni sekolah swasta yang berasal dari sekolah swasta berstatus madrasah dan pesantren mendominasi berbagai kegiatan keagamaan di masyarakat.

Kepemimpinan spiritual menjadi modal agama bagi sekolah swasta untuk memperoleh dominasi dalam masyarakat terutama dalam konteks pendidikan. Hal tersebut berdasarkan hasil angket yang telah disebar. Hasil angket dari 301 responden terkait kepemimpinan spiritual, untuk sekolah madrasah dan pesantren, ada 250 responden atau $83.05 \%$ responden yang mengatakan orang sekolah swasta selalu menjadi pemimpin dalam kegiatan keagamaan yang ada dalam masyarakat. Sisanya yaitu hanya 51 orang responden atau $16.95 \%$ responden yang tidak mengatakan orangorang sekolah swasta selalu menjadi pemimpin dalam kegiatan keagamaan yang ada dalam masyarakat (lihat diagram 2).

Kepemilikan modal agama yang berbeda antara sekolah negeri dan sekolah swasta. Modal agama yang berbeda mencakup (1) kepercayaan masyarakat terhadap sekolah swasta (madrasah dan pesantren) sebagai sekolah berbasis agama memiliki mata pelajaran pendidikan agama Islam sehingga bisa mengajarkan anak-anak mereka menjadi anak yang lebih memiliki pengetahuan keterampilan dan sikap spiritual yang lebih baik dibandingkan menyekolahkan anak mereka ke sekolah negeri.

Diagram 2. Kepemilikan modal agama sekolah swasta dalam hal kepemimpinan spiritual

Orang-orang Sekolah swasta selalu memimpin kegiatan keagamaan di masyarakat

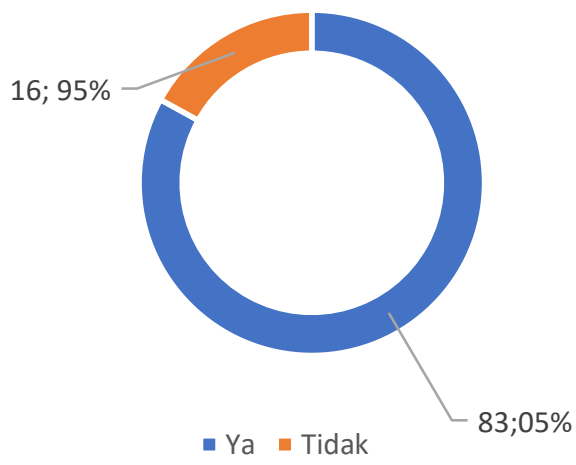

Sumber: Olah Data Hasil Penelitian 
Tren pendidikan anak yang terbaik di masyarakat adalah sekolah swasta dengan status pesantren atau madrasah, ditunjang oleh program kementrian agama "madrasah lebih baik, lebih baik madrasah" dan "ayo mondok" yang dibuat dengan dasar untuk memperbaiki perilaku generasi muda sekarang ini yang kurang memiliki akhlak atau karakter. Karakter merupakan bisa ditanamkan melalui proses pendidikan di sekolah (Suardi et al., 2018), proses pembelajaran (Kanji et al., 2019; Suardi et al., 2019), diintegrasikan dengan kearifan lokal, melalui model kolaborasi sosial (Suardi, Agustang, \& Sahabuddin, 2020), namun tetap harus dievaluasi (Kanji et al., 2019), karena pendidikan karakter bukan hanya memiliki faktor pendukung namun juga memiliki faktor penghambat (Kanji et al., 2020). Pendidikan akhlak, karakter atau nilai moral dapat dikembangkan di jenjang sekolah (Suardi, Nursalam, \& Kanji, 2020), dan di perguruan tinggi (Suardi, Nursalam, \& Kanji, 2020). Hal tersebut membuat banyak orang tua yang menyekolahkan anak mereka di madrasah dan pesantren.

Masyarakat memiliki kepercayaan kepada sekolah swasta yang berstatus madrasah dan pesantren beberapa aktor sekolah swasta lebih memilih anak mereka sekolah di pesantren dibandingkan di sekolah negeri. Simbol agama menjadi daya tarik masyarakat untuk mempercayakan anak mereka untuk didik di sekolah pesantren. Hal tersebut juga membuat sekolah swasta menjadikan simbol agama sebagai daya tarik kepercayaan masyarakat. Sehingga menimbulkan masyarakat memberikan stereotip positif untuk sekolah swasta yang berstatus madrasah dan pesantren bukan hanya sebagai"sekolah berbasis agama", namun juga sebagai "sekolah pencetak penghafal AlQur'an", "sekolah calon penceramah atau ustadz/ustadzah" sedangkan untuk siswa adalah "siswa penghafal Al-Qur'an, Siswa penceramah, Ustadz atau Ustadzah. (2) Kepemimpinan spiritualitas yang dilakukan di masyarakat didominasi oleh aktor-aktor sekolah swasta dibandingkan dengan aktor-aktor sekolah negeri seperti menjadi imam masjid, menjadi penceramah pada bulan suci Ramadhan, khatib khutbah jumat, khatib pada hari raya idul fitri dan idul adha, pencemaran takziyah, penceramah acara pernikahan dan lain-lain. Kepemimpinan spiritual menjadi modal bagi sekolah swasta untuk mendapatkan simpati dari masyarakat untuk menetralisir dominasi dan hegemoni aktor sekolah negeri dalam kehidupan masyarakat sebagai kelas high level dalam konteks pendidikan di Kecamatan Bissappu.

Kepemilikan modal ekonomi dalam suatu arena membentuk suatu praktik pendidikan yang lebih baik (Bourdieu, 1993), kepemilikan modal ekonomi mendorong rasa berhak yang kuat terhadap hak istimewa (Xu, 2017), rasa berhak yang kuat terhadap hak istimewa dapat berakibat pada embrio kekerasan simbolis (Huot, 2017). Akumulasi penguasaan modal oleh sekolah negeri mencakup modal ekonomi, sosial, budaya dan simbolik. Akumulasi modal menentukan kelas sosial sekolah dalam masyarakat. Kelas terbagi menjadi tiga tingkatan yaitu kelas populer sebagai kelas yang non akumulasi modal, kelas borjuasi kecil yang selalu melakukan imitasi modal dan kelas dominan yang memiliki akumulasi modal (Bourdieu, 1993). Sekolah negeri melalui akumulasi modal yang lebih bagus menempatkan diri sebagai kelas dominan dengan kepemilikan akumulasi modal dan memiliki peluang melakukan kekerasan simbolik terhadap sekolah swasta sebagai kelas borjuasi dan populer, karena modal ekonomi, sosial, budaya dan simbolik yang dimiliki berkontribusi yang sangat besar terhadap praktik kekerasan simbolis (Huot, 2017). Kepemilikan terhadap modal mampu menempati dominasi, mengubah dominasi, mempertahankan dan memperebutkan dominasi (Suardi, Agustang, \& Jumadi, 2020b). Inilah yang dimaksudkan oleh (Bourdieu, 
1993) sebagai kekuasaan simbolik (symbolic power) berdasarkan akumulasi modal sebagai embrio kekerasan simbolik (symbolic violence).

Melalui kuasa yang dimiliki sekolah negeri sebagai kelas dominan memiliki kekuasaan terhadap sekolah swasta melalui akumulasi modal yang dimiliki yaitu modal ekonomi, modal sosial, modal budaya dan modal simbolik (Suardi, Agustang, \& Jumadi., 2020b) yang dimiliki sehingga menimbulkan embrio kekerasan simbolik terhadap siswa sekolah swasta dan untuk aktor dan sekolah swasta. Meskipun sekolah swasta memiliki modal ekonomi, modal sosial, modal budaya dan modal simbolik namun belum mampu membuat sekolah swasta naik menjadi kelas dominan. Modal baru yang bisa menjadi potensi bagi sekolah swasta merebut dominasi adalah kepemilikan modal agama yang kurang dimiliki oleh sekolah negeri yaitu modal agama dalam bentuk kepercayaan masyarakat dan kepemimpinan spiritual sebagai modal baru yang sangat potensial untuk merebut dominasi sebagai kelas high level dalam kontestasi dalam dunia pendidikan.

Gambar 1. Akumulasi Modal (ekonomi, sosial, budaya, simbolik dan agama)

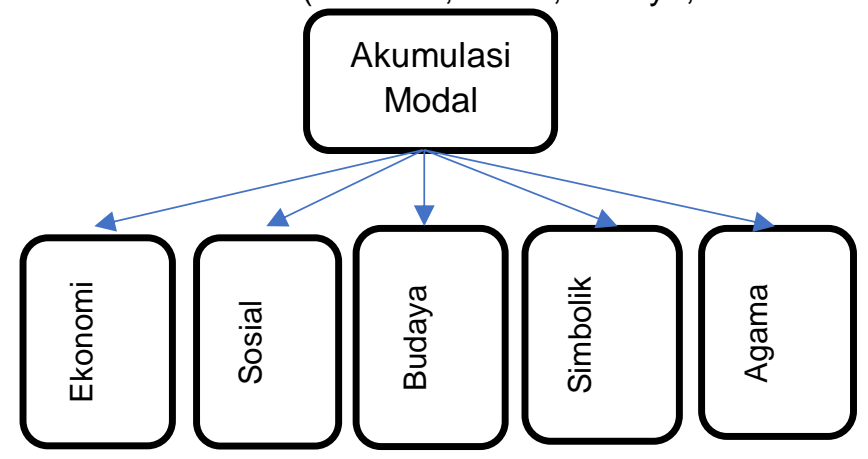

Sumber: Diolah dari Bourdieu, 1993

Kepercayaan masyarakat dan kepemimpinan spiritual menjadi modal bagi sekolah swasta untuk mendapatkan simpati dari masyarakat untuk menetralisir dominasi dan hegemoni aktor sekolah negeri dalam kehidupan masyarakat sebagai kelas high level dalam konteks pendidikan di Kecamatan Bissappu. Agama menjadi simbol yang memiliki kekuatan untuk memonopoli dan namun tetap memiliki modal budaya (Bourdieu, 1993), meskipun Mulkan memasukkan modal komunitas agama sebagai modal sosial. Agama sebagai modal sosial seperti penguasaan dan ketertarikan terhadap agama (Finke \& Dougherty, 2002), atau aspek religius, identitas agama, sosialisasi agama maupun jaringan sosial keagamaan (Park \& Smith, 2000), manusia religius (lannaccone, 1990), intensitas keagamaan (Forbes \& Zampelli, 2014), namun belum ada yang menggunakan kepercayaan masyarakat dan kepemimpinan spiritual sebagai modal agama.

\section{KESIMPULAN}

Modal agama menjadi hal yang dominan yang dimiliki oleh sekolah swasta yang bisa dioptimalkan untuk merebut dominasi dalam ranah pendidikan agar siswa tidak mengalami kekerasan simbolik. Bentuk modal sosial yang dimiliki oleh sekolah swasta adalah (i) kepercayaan masyarakat terhadap sekolah swasta dalam memberikan pembelajaran agama, karakter atau nilai-nilai sosial, sekolah swasta mendapatkan kepercayaan dari masyarakat untuk pembelajaran agama, karakter atau nilai-nilai sosial dengan persentase $71.77 \%$, sedangkan untuk sekolah negeri hanya $28.23 \%$ (ii) 
kepemimpinan spiritual yang selalu didominasi oleh aktor-aktor sekolah swasta dalam berbagai kegiatan keagamaan, dengan persentase $83.05 \%$, dibandingkan sekolah negeri yang hanya $16.95 \%$.Saran untuk peneliti selanjutnya untuk mengkaji efektifitas modal agama untuk mengatasi kekerasan simbolik di Kabupaten Bantaeng. Untuk akademisi bisa menjadi modal agama sebagai modal baru dalam akumulasi modal.

\section{DAFTAR PUSTAKA}

Bourdieu, F. (1993). The Field Of Cultural Production (R. Johnson). Columbia University Press.

Creswell, J. W. (2017). Research Design: Qualitative, Quantitative, And Mixed Methods Approaches. Sage Publication.

Finke, R., \& Dougherty, K. D. (2002). The Effects Of Professional Training: The Social And Religious Capital Acquired In Seminaries. Journal For The Scientific Study Of Religion, 41(1), 103-120. Https://Doi.Org/10.1111/1468-5906.00104

Forbes, K. F., \& Zampelli, E. M. (2014). Volunteerism: The Influences Of Social, Religious, And Human Capital. Nonprofit And Voluntary Sector Quarterly, 43(2), 227-253. Https://Doi.Org/10.1177/0899764012458542

Huot, S. (2017). "Doing" Capital: Examining The Relationship Between Immigrants' Occupational Engagement And Symbolic Capital. Migration Studies, 5(1), 29-48. Https://Doi.Org/10.1093/Migration/Mnw023

lannaccone, L. R. (1990). Religious Practice: A Human Capital Approach. Journal For The Scientific Study Of Religion, 29(3), 297. Https://Doi.Org/10.2307/1386460

Kanji, H., Nursalam, Nawir, M., \& Suardi. (2020). Supporting And Inhibiting Factors Of Character Education In Learning Social Studies At Primary Schools. Jed (Journal Of Etika Demokrasi), 5(1), 1-14. Https://Doi.Org/10.26618/Jed.V5i1.2966

Kanji, H., Nursalam, Nawir, M., \& Suardi. (2019). Model Integrasi Pendidikan Karakter Dalam Pembelajaran IImu Pengetahun Sosial Di Sekolah Dasar. Jurnal Pendidikan Dasar Perkhasa, 5(2), 104-11. Https://Doi.Org/10.31932/Jpdp.V5i2.458

Larson, J., Merry, S., Rodr, C., Brigham, J., \& Diego, L. (2003). Symbolic Power Without Violence? Critical Comments On Legal Consciousness Studies. International Journal For The Semiotics Of Law, 16, 363-393. Https://Doi.Org/10.1023/B:Sela.0000013846.61056.A3

Nursalam, Manda, D., \& Suardi. (2018). Sexual Abuse (Study Of Child Sexual Abuse In Poleang District Bombana Regency). Palarch's Journal Of Archaralogy Of Egypt/Egyptogy, 17(2), 232-240. Http://Www.Palarch.NI/Index.Php/Jae/Article/View/210/155

Nursalam, \& Syarufuddin., S. (2016). Teori Sosiologi Klasik, Modern, Posmodern, Saintifik, Hermeneutik, Kritis, Evaluatif, Dan Integratif. Writing Revolution.

Park, J. Z., \& Smith, C. (2000). "To Whom Much Has Been Given...”: Religious Capital And Community Voluntarism Among Churchgoing Protestants. Journal For The Scientific Study Of Religion, 39(3), 272-286. Https://Doi.Org/10.1111/00218294.00023

Suardi. (2018). Sosiologi Komunitas Menyimpang (Vol.1). Writing Revolution.

Suardi, Agustang, A., \& Jumadi. (2020a). Symbolic Violence Towards Students In The Context Of The Existence Of The Stereotypical Frames Of Lecturers And Students In The Higher Education System In Indonesia. Palarch's Journal Of Archaralogy Of Egypt/Egyptogy, Http://Www.Palarch.NI/Index.Php/Jae/Article/View/210/155

Suardi, Agustang, A., \& Jumadi. (2020b). The Symbolic Violence Towards Private School Students Through The Frame Stereotype In Bantaeng District Of Indonesia. The International Conference On Innovations In Social Sciences And Education, 578-588. 
Suardi, Agustang, A., \& Sahabuddin, J. (2020). Model Kolaborasi Sosial Pendidikan Karakter Di Sekolah Swasta Kecamatan Bissappu Kabupaten Bantaeng. Prosiding Seminar Dan Diskusi Pendidikan Dasar, 1-11. Http://Journal.Unj.Ac.Id/Unj/Index.Php/Psdpd/Article/View/17769

Suardi, Nursalam, \& Kanji, H. (2020). Penguatan Pendidikan Karakter: Berbasis Integratif Moral Di Perguruan Tinggi (Vol.1). Cv. Aa. Rizky.

Suardi, S., Herdiansyah, H., Ramlan, H., \& Mutiara, I. A. (2019). Implementasi Pendidikan Karakter Melalui Mata Pelajaran Pendidikan Kewarganegaraan Di Sma Jaya Negara Makassar. Jed (Jurnal Etika Demokrasi), 4(1), 22-29. Https://Doi.Org/10.26618/Jed.V4i1.1983

Suardi, S., Megawati, M., \& Kanji, H. (2018). Pendidikan Karakter Di Sekolah (Studi Penyimpangan Siswa Di Mts Muhammadiyah Tallo). Jed (Jurnal Etika Demokrasi), 3(1), 75-84. Https://Doi.Org/10.26618/Jed.V3i1.1979

Xu, C. L. (2017). Mainland Chinese Students At An Elite Hong Kong University: HabitusField Disjuncture In A Transborder Context. British Journal Of Sociology Of Education, 38(5), 610-624. Https://Doi.Org/10.1080/01425692.2016.1158642 